\title{
Una etnografía sobre personas viviendo con sida, calidad de la atención y construcción de la enfermedad
}

\author{
An ethnography of people living with AIDS, the quality of \\ their healthcare and construction of the disease
}

\author{
Evangelina Anahí Bidegain ${ }^{i}$ \\ ' Doctoranda, programa de antropología social/Centro de Investigaciones y Estudios Superiores en Antropología Social. \\ Ciudad de México - México \\ orcid.org/0000-0001-5563-1713 \\ evabidegain@gmail.com
}

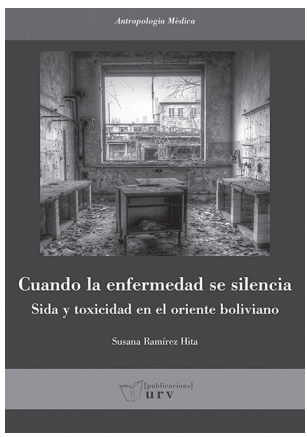

RAMIREZ HITA, Susana. Cuando la enfermedad se silencia: sida y toxicidad en el oriente boliviano. Tarragona: Universidad Rovira i Virgili. 2016. 216p.
Este nuevo estudio de Ramírez Hita (2016) presenta un doble interés para la antropología médica. Por un lado, el valor académico del trabajo con material de campo y fuentes secundarias. Por el otro, el interés de salud pública de problematizar la toxicidad y la relación con el padecimiento del sida.

El estudio, producto de dos consultorías que Ramírez Hita realizó sobre el sida en Bolivia entre 2009 a 2011 y del 2013 al 2015, fue editado en el 2016 y consta de dos partes. La primera sobre la construcción del concepto del sida y la segunda, sobre las condiciones de los servicios de salud y de las personas viviendo con sida.

En su búsqueda por la "mirada global" sobre la situación sanitaria, incluye las problemáticas generales de salud en las ciudades de Cobija, Trinidad y Santa Cruz en el oriente boliviano, seleccionadas porque dos de ellas presentaban menores tasas de casos nuevos de

sida y tan solo Santa Cruz presentaba mayores tasas a nivel país. La pregunta principal cuestiona el por qué los datos epidemiológicos oficiales estaban bajo sub registro y las razones de las casi 100 muertes de sida en menos de un año. Diseña el estudio a partir de indagar la construcción de las representaciones de los distintos actores sociales; cómo percibían el problema de la calidad y cómo influía el Programa Nacional de ITS, VIH y sida en la vida cotidiana de estos sujetos sociales. La metodología procuró recuperar las subjetividades de los actores tratando de articular los significados y la acción social e incorporando las dimensiones políticas, ideológicas y económicas que influencian la adecuada o deficiente calidad de la atención. Entrevistó a 36 personas viviendo con la enfermedad, 11 cuidadores domésticos, la mayoría usuarios de servicios públicos de salud y en condición de extrema pobreza, y al personal de salud que los atiende, considerando el aspecto relacional del padecimiento. Además de las entrevistas y observación en servicios públicos de atención 
de salud, revisa los informes de consultoría y agencias y las noticias periodísticas desde el 2012 al 2015 que mencionaran contaminación ambiental, toxicidad y transgénicos.

La hipótesis inicial del estudio era que habían factores ideológicos culturales en los grupos quechua y aymara que han impedido que se tomaran oportunamente medidas necesarias para que el sida no avanzara. Sin embargo, indagará la construcción de la enfermedad, y cómo se incorpora la toxicidad al revisar la posición científica disidente a la existencia de un virus HIV, que considera que el sida es causado por la exposición a múltiples factores, entre los que se ubican la toxicidad por sustancias químicas, por agentes estresantes, por agentes nutricionales, malnutrición.

Al repasar el rol de las agencias y sida, revisa al Center for Disease Control (CDC) de Estados Unidos que elabora protocolos que son adoptados por la OMS. En 1983 el CDC definía 12 entidades clínicas para diagnosticar sida, en 1987 definió 24 y en 1993 amplió a 26. En África, en el año 1985, se definieron criterios clínicos mínimos como suficientes para el diagnóstico positivo: fiebre, pérdida de peso, diarrea y tos que no se corresponda a una tuberculosis, junto con sarcoma de kaposi, herpes zoster, candidiasis. La serología, empero, puede dar falsos positivos en caso de malnutrición, tuberculosis, malaria, quimioterapia, reacción cruzada ante una vacuna, artritis, gripe. Esto le lleva al segundo aspecto: cómo se construye el concepto de VIH sida en Bolivia. Para ello revisa cómo se conforma la estructura de financiamiento y de gestión de los programas de VIH sida en Bolivia luego del año 2002, mostrando las influencias económicas, técnicas e ideológicas en las políticas y en la cooptación de los distintos actores en las distintas fases de la construcción ideológica de la dolencia.

Junto con agencias internacionales, el programa de Infecciones de Transmisión Sexual (ITS), VIH y sida en Bolivia, que se inicia en 1986, creo programas dirigidos a las trabajadoras sexuales y a la comunidad gay, reafirmando la idea de transmisión sexual y manteniendo la estigmatización con un mensaje a la población de que un (solo) grupo social porta la enfermedad. La población heterosexual debe concurrir a los mismos centros a los que se dotó de ginecólogos pero no médicos generalistas. La base de datos de ITS VIH no se comparte con el Servicio Nacional de Información Estadística, lo cual contribuye al estado de sub registro general.

En la revisión de los estudios que realizan el sector salud, distintas ONGs, asociaciones civiles y de cooperación internacional y la academia, consideran que el problema del sida es analizado predominantemente de manera cuantitativa - incluso los datos cualitativos - y focalizados en algunos grupos sociales, describiendo la realidad observada sin problematizarla. Son inexistentes los estudios desde la biología o desde la química farmacológica y desde la socioantropología. Da cuenta del hecho de que el AZT que monopoliza la farmacéutica Pfizer empezó como medicamento para el cáncer que por su toxicidad no fue recomendado por la Foods and Drugs Administration y, sin embargo, luego ingresa como el medicamento recomendado para el tratamiento del sida. En 2002, un Fondo Mundial participa en la compra de medicamentos y distintas ONGs van actuando en la gestión de la distribución en Bolivia. Las recomendaciones del tratamiento antirretroviral de las Guías Técnicas para personal de salud son contradictorias y ambiguas en Bolivia, librando a la intuición del médico cuándo comenzar y cuándo suspender el tratamiento, además de que no incluyen los conflictos de interés de los estudios. 
En la segunda parte del libro, la autora presenta la calidad de la atención. La precariedad de la infraestructura de los servicios públicos de salud, junto con la proliferación de practicantes médicos y falta de insumos para el trabajo y el confort de los pacientes en los servicios de atención. Así, los bancos de sangre no cuentan con recursos suficientes para pruebas serológicas, elementos de protección como guantes, barbijos, protectores oculares, a lo que se suma el estrés laboral, los bajos salarios y la falta de personal.

Los pacientes tienen un lugar destacado en el texto con testimonios de cómo fueron las circunstancias donde le diagnostican la enfermedad, los encuentros y desencuentros con los servicios de salud y las dificultades de conciliar el tratamiento y sostener una reproducción social sin dinero para comer y para dejar el cuidado de los hijos en instancias de internación. Condiciones que conllevan a intentos de suicidios. El sufrimiento que el sistema de salud no puede resolver es vivido como violencia (estructural) por las personas afectadas.

Para concluir, la autora muestra cómo coinciden el aumento de cultivos trangénicos con los países con mayor carga de diagnósticos de sida. Nos invita a reflexionar: "Llama la atención que las semillas transgénicas, así como los pesticidas y herbicidas, sean comercializados por la empresa Monsanto, que ésta tenga relación con los laboratorios productores de antirretrovirales y que, además, se haya instalado en zonas con alta contaminación ambiental debido a la extracción minera e hidrocarburífera" (p.216).

\section{REFERENCIA}

RAMIREZ HITA, Susana.

Cuando la enfermedad se silencia: sida y toxicidad en el Oriente boliviano. Tarragona: Universidad Rovira i Virgili. 2016. 